\title{
Training the Trainer in Australia - A Critical Analysis
}

\author{
Stanislaw Paul Maj ${ }^{1}$ \\ ${ }^{1}$ Consultant, Joondalup, Western Australia \\ Correspondence: Stanislaw Paul Maj, Joondalup, 6027, Western Australia. E-mail: spaulmaj@gmail.com \\ Received: July 16, 2015 \\ Accepted: October 17, $2015 \quad$ Online Published: November 30, 2015 \\ doi:10.5539/mas.v9n13p263 \\ URL: http://dx.doi.org/10.5539/mas.v9n13p263
}

\begin{abstract}
Within the Australian Further Education sector lecturers are required to complete the Certificate IV in Training and Assessment (TAE40110). Whilst it is recognized that lecturers in this sector are required to meet the needs of a wide diversity of students the ability to deliver training and conduct workshops is of paramount importance. There are a number of problems with studying the TAE that include insufficient weighting of units concerned with pedagogy and variable contact hours. The result is lecturers who complete the TAE may not be adequately prepared to conduct their role as teachers and trainers.
\end{abstract}

Keywords: training, training packages, vocational education, TAE

\section{Introduction}

\subsection{The Australian Further and Higher Education System}

Modern economies are based on a highly skilled and educated workforce. Within Australia there are three principle education sectors - Schools, Vocational Education \& Training (VET) (aka Further Education) and Higher Education (Universities). In order to meet the projected needs of industry and commerce the Australian Government proposed the expansion of the VET sector. Significantly the reforms identified problems with VET teaching quality and the need to address this problem,

'While business and students generally report a high degree of satisfaction with their VET experience, a number of reviews have identified quality as a key concern, especially in teaching and assessment practices'. (Department of Education 2012)

\subsection{Australian Training Packages}

Australian Further Education (FE) is based on training packages. Training packages are developed and maintained by industry specific Industry Skills Councils (ISCs) with clearly defined development, validation and endorsement processes. Training packages are endorsed by the National Skills Standards Council (NSSC). A training package consists of three nationally endorsed components - units of competency, assessment guidelines and qualifications framework. A qualification consists of a combination of units of competency appropriate to the specific discipline area. Qualifications are aligned to the Australian Qualifications Framework (AQF). The $\mathrm{AQF}$ provides national consistency for qualification scope and quality thereby facilitating pathways between qualifications.

For example, the Automotive Industry Retail, Service and Repair Training Package (AUR05) define the range of qualifications that are available in this field from the introductory Certificate I in Automotive (AUR10105) to the Diploma of Automotive Technology (AUR50205). A Certificate I is designed to provide students with basic competencies such as: demonstrate basic practical skills; perform a sequence of routine tasks given clear direction etc. By contrast a Diploma level student displays competencies that include: analyze and plan approaches to technical problems; transfer and apply theoretical concepts and/or technical skills to a range of situations. Each award provides: course description; pathways information; licensing/regulatory information; employability skills summary and packaging rules. The packaging rules define the units of competency that must be completed - core and elective.

A unit of competency in the Certificate course AUR10105 is 'Test, service and maintain battery storage systems' (AURE118671A). This unit of competency has a small but clearly defined skill set. A unit of competency in the Diploma course AUR50205 is 'Analyze and evaluate electrical and electronic faults in monitoring/protection systems' (AURT575593A). This unit represents a much higher level of training. 
Significantly training packages specify both the skills and knowledge to perform in the workplace but do not define how an individual should be taught and trained. Accordingly lecturers in the Further Education sector are required to complete and demonstrate continuous development of their Vocational Education and Training (VET) skills and knowledge and industry competence through professional development training.

\subsection{Certificate IV in Training and Assessment (TAA40104)}

Typically the Further Education sector employs staff with skills and experience in a given domain such as automotive. New academics are required to complete the Certificate IV in Training and Assessment (TAE40110) from the Training and Education (TAE10) training package consisting of seven core and three elective units. The original Certificate IV in Assessment and Workplace Training (BSZ40198) was replaced by the Certificate IV in Training and Assessment (TAA40104) in order to address quality concerns. The TAA consisted of 12 core units with 2 elective unit and a recommended 305 contact hours. On behalf of the Government of Australia bodies such as the National Centre for Vocational Education Research (NCVER), Innovation \& Business Skills Australia (IBSA), Precision Consulting etc. conducted annual nationwide surveys on the quality of the TAA. The NCVER 2010 survey found that,

'Significantly, a majority of participants commented that they had entered the program to learn much more about how to teach and were disappointed when this did not occur to the extent they had expected'.(Clayton 2010)

A complimentary study of the TAA in the same year also indicated quality problem with half of the survey respondents considering that the qualification was inadequate or inappropriate. According to Moodie,

'Stakeholder and RTO interviewees who thought that the Certificate IV was inadequate said there was an insufficient focus on teaching, pedagogy, how people learn, diversity and inclusiveness and that there was too much focus on instrumental aspects about CBT, which while important, were not as important as helping teachers understand how to teach'. (Moodie 2010)

\subsection{Quality Teaching Elements}

There is considerable and varied literature regarding what constitutes quality teaching and hence how teachers should be taught. According to the Department of Education and Training Professional Support and Curriculum Directorate (State of NSW) there are three principle dimensions each with a number of elements:

- Dimension 1: Intellectual Quality

- Elements: deep knowledge, deep understanding, problematic knowledge, higher-order thinking, meta-language, substantive communication.

- Dimension 2: Quality Learning Environment

- Elements: explicit quality criteria, engagement, high expectations, social support, students' self-regulation, student direction

- Dimension 3: Significance

- Elements: background knowledge, cultural knowledge, knowledge integration, inclusivity, connectedness, narrative

Arguably all the dimensions and elements are important but the report provides no explicit weightings. This is potentially important if a teaching qualification is of limited duration. According to the McKenzie report (Company 2007) the most important factor that improves teaching and learning outcomes is the quality of the teacher.

'The experiences of these top school systems suggests that three things matter most: 1) getting the right people to become teachers, 2) developing them into effective instructors and 3) ensuring that the system is able to deliver the best possible instruction for every child.'

Furthermore the McKenzie report states that,

'The quality of the outcomes for any school system is essentially the sum of the quality of the instruction that its teachers delivery.' And also, 'Ensuring that teachers have that knowledge and capacity is not easy. Delivering excellent instruction requires teachers to develop a highly sophisticated set of skills.'

\subsection{Certificate IV in Training and Assessment (TAE40110)}

The Certificate IV in Training and Assessment (TAE4011) was designed to address the problems identified with the Certificate IV in Training and Assessment (TAA40104). Completion of the TAE40110 is a quality assurance that lecturers will be able to teach students in their own discipline area. The seven core units of the TAE are designed to prepare lecturers for training package design, delivery, facilitation and assessment (table 1). 
Table 1. TAE core units

\begin{tabular}{|c|c|c|c|c|c|c|}
\hline 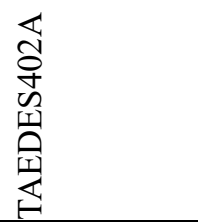 & 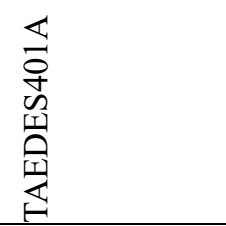 & 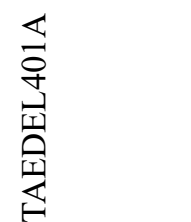 & 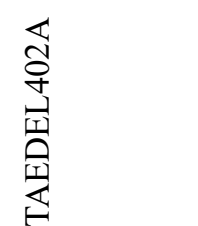 & 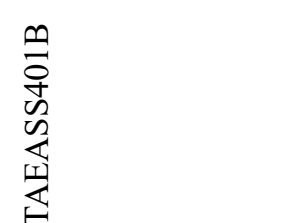 & 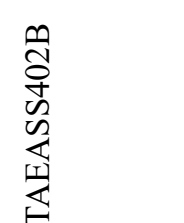 & 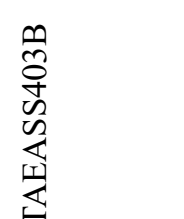 \\
\hline $\begin{array}{l}\text { Use training } \\
\text { packages } \\
\text { and } \\
\text { accredited } \\
\text { courses to } \\
\text { meet client } \\
\text { needs }\end{array}$ & $\begin{array}{l}\text { Design and } \\
\text { develop } \\
\text { learning } \\
\text { programs }\end{array}$ & $\begin{array}{l}\text { Plan, } \\
\text { organize } \\
\text { and deliver } \\
\text { group-based } \\
\text { learning }\end{array}$ & $\begin{array}{l}\text { Plan, } \\
\text { organize } \\
\text { and } \\
\text { facilitate } \\
\text { learning in } \\
\text { the } \\
\text { workplace }\end{array}$ & $\begin{array}{l}\text { Plan assessment } \\
\text { activities and } \\
\text { processes }\end{array}$ & $\begin{array}{l}\text { Assess } \\
\text { competence }\end{array}$ & $\begin{array}{l}\text { Participate } \\
\text { in } \\
\text { assessment } \\
\text { validation }\end{array}$ \\
\hline $\begin{array}{l}\text { To use } \\
\text { training } \\
\text { packages } \\
\text { and } \\
\text { accredited } \\
\text { courses as } \\
\text { tools to } \\
\text { support } \\
\text { industry, } \\
\text { organization } \\
\text { and } \\
\text { individual } \\
\text { competency } \\
\text { development } \\
\text { needs }\end{array}$ & $\begin{array}{l}\text { To } \\
\text { conceptualize, } \\
\text { design, } \\
\text { develop and } \\
\text { review } \\
\text { learning } \\
\text { programs to } \\
\text { meet an } \\
\text { identified } \\
\text { need for a } \\
\text { group of } \\
\text { learners }\end{array}$ & $\begin{array}{l}\text { To plan, } \\
\text { organize } \\
\text { and deliver } \\
\text { training for } \\
\text { individuals } \\
\text { within a } \\
\text { group }\end{array}$ & $\begin{array}{l}\text { To plan, } \\
\text { organize } \\
\text { and } \\
\text { facilitate } \\
\text { learning for } \\
\text { individuals } \\
\text { in a } \\
\text { workplace }\end{array}$ & $\begin{array}{l}\text { To plan and } \\
\text { organize the } \\
\text { assessment } \\
\text { process, including } \\
\text { recognition of } \\
\text { prior learning } \\
\text { (RPL), in a } \\
\text { competency-based } \\
\text { assessment } \\
\text { system }\end{array}$ & $\begin{array}{l}\text { To assess } \\
\text { the } \\
\text { competency } \\
\text { of a } \\
\text { candidate }\end{array}$ & $\begin{array}{l}\text { To } \\
\text { participate } \\
\text { in an } \\
\text { assessment } \\
\text { validation } \\
\text { process }\end{array}$ \\
\hline
\end{tabular}

There are three main clusters: two design units (DES), two delivery units (DEL) and three assessment units (ASS). Each unit has a set of elements of competency with associated performance criteria.

Elective units are available to enhance different aspects of the core units such as 'Make a presentation', 'Provide work skill instruction' and 'Mentor in the workplace.'(Table 2). The TAE was analyzed to determine if it addressed the problems identified with the TAA precursor.

Table 2. TAE elective units

\begin{tabular}{lll}
\hline BSBCMM401A & TAEDEL301A & TAEDEL404A \\
\hline Make a presentation & Provide work skill instruction & Mentor in the workplace \\
To prepare, deliver and review a & To conduct individual and group & To establish and develop a \\
presentation to a target audience & instruction and demonstrate work \\
& skills using existing learning & relationship with a learner, in \\
resources in a safe and comfortable & particular an apprentice or \\
& teaching environment & $\begin{array}{l}\text { trainee employed by, or } \\
\text { undertaking work placement } \\
\text { in a workplace }\end{array}$ \\
\hline
\end{tabular}

\section{Method}

The TAE has twenty nine required skills (Table 3) which the author mapped against all of the core units. 
Table 3. TAE required skills

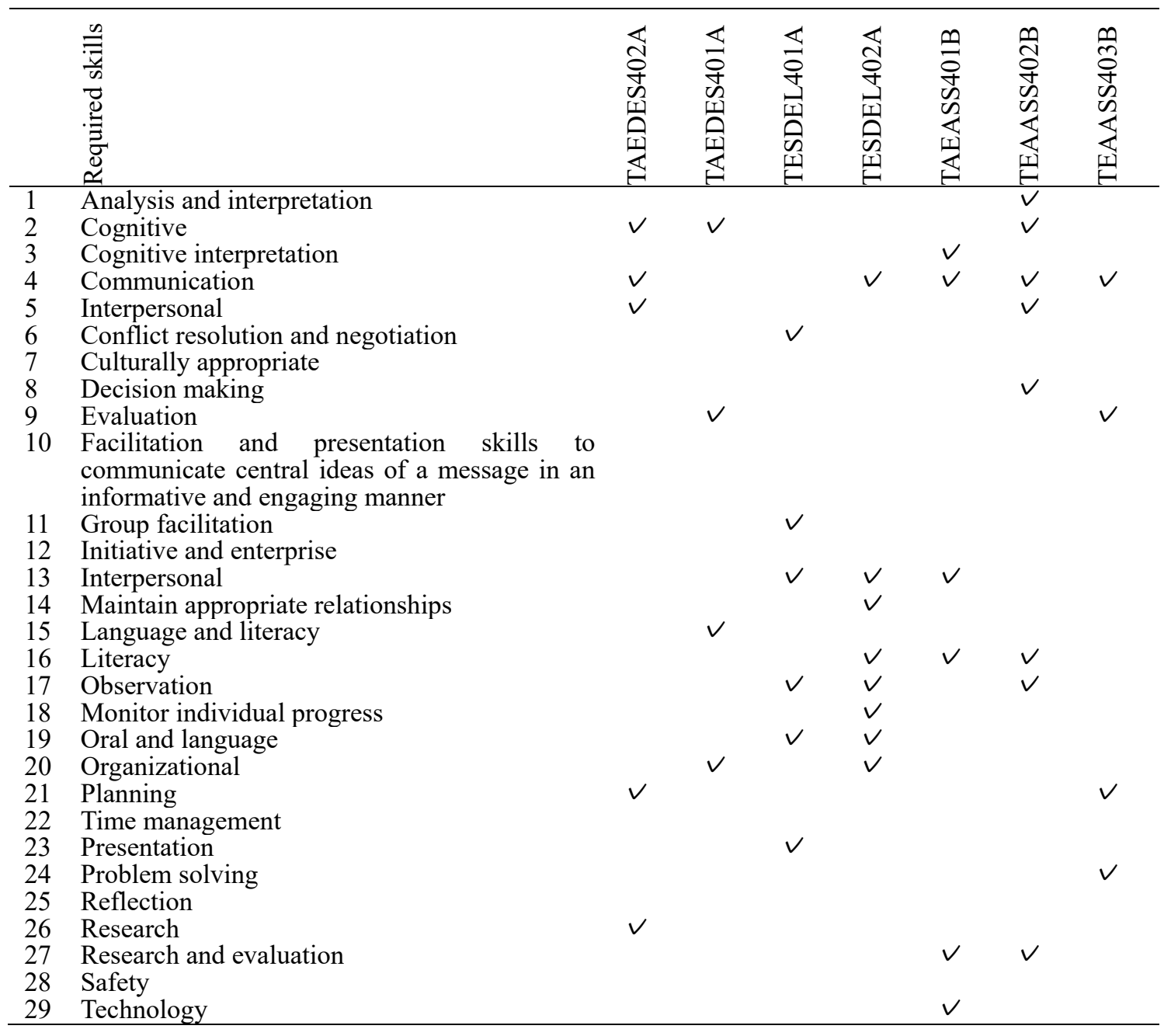

The core units mapped to most of the required skills with elective units providing the other required mappings. IT can be concluded that these required skills are of a generic nature that would be applicable to many different professions such as sales representative or marketing coordinator. By contrast a teacher must be able to facilitate learning by:

- give a lecture

- conduct a workshop

- design educational materials

- use a Learning Management System (LMS)

The TAE has seventy five required knowledge items. The fifteen knowledge items identified to be directly relevant to teaching are:

1. Different delivery modes and methods

2. Instructional design principles relating to different design options for learning program design and structure

3. Learner group profile, including characteristics and needs of individual learners in the group

4. Learning principles

5. Learner characteristics and needs

6. Availability and types of different relevant learning resources, learning materials and pre-developed learning activities 
7. Leaning styles

8. Leaning theories

9. Methodology relating to developing and documenting new learning activities and related learning materials

10. Range of presentation aids and materials available to support presentations

11. Different delivery methods and techniques appropriate to face-to-face group delivery

12. Introductory knowledge of different learning styles and how to encourage learning in each

13. Introductory knowledge of learning principles and learning styles

14. Training products and strategies for learning

15. Training techniques that enhance learning and when to use them

\section{Results}

Whilst this list of teaching knowledge items may appear to be comprehensive seven significant problems were identified.

\subsection{Identified Problems}

\#1 Core units

Four of these required knowledge items are not in the core units.

\#2 Learning Management Systems

Learning Management Systems are the norm within all educational sectors and an understanding of how they are used, it can be argued, should therefore be core material.

\#3 Educational units

It is recognized that lecturers have the challenge of a wide diversity of students, courses and expectations on-campus; off-campus, VET in schools (VETiS); Associate degrees etc. (Wheelan 2010). A lecturer typically is required to provide 21 hours of student contact with an associated 12.5 hours of related development activities. The predominant activity for a lecturer is teaching students via lectures and associated workshops. However fifteen knowledge items directly relevant to teaching represent only $20 \%$ of the total TAE knowledge items. The remainder of the TAE is concerned with issues such as: compliance, validation, moderation, mentoring, workplace facilitation, Australian Quality Training Framework (AQTF) etc. These are important topics but arguably the predominant requirement of a lecturer is to facilitate learning.

\#4 Contact hours

The nominal contact time for completion of the TAE is 290 hours as determined from the National Endorsed, State Implementation and Classification Curriculum Development information available through VETinfoNET (VetInfoNet). However numerous Registered Training Organizations (RTOs) provide students with the opportunity to complete the TAE in a variety of modes and in a range of time frames. It is possible, according to some RTOs, to complete the TAE in five days (circa 40 hours). Other RTOs offer study week ends over a 14 week period (circa 84 hours). It is possible to study the TAE online, face to face and by distance and blended learning modes. An Internet search sample of 12 RTOs revealed the typical delivery timeframe to be between 5 to 10 days with a number of pathways offered to achieving the qualification, namely:

- Face-to-face combined with completion of further requirements in the students time

- Recognition of Prior Learning (RPL) for students with prior training and/or assessment experience and/or with higher educational qualification

- Blended learning for students with past experience and training that would be complimented by undertaking a combination of the above methodologies

Whilst it is recognized that RPL may be appropriate the significant reduction in nominal contact hours is potentially problematic. There were similar concerns regarding the Certificate IV in Training and Assessment (TAA40104). The National Quality Council (NQC), National Strategic Industry Audit reported a low level of confidence in this award. According to the NQC, 
'A number of RTOs that deliver this qualification attempt to deliver it in a mode that does not produce quality students - they offer it in a very short time frames and their graduates have little or no knowledge of VET structures or AQTF requirements.'

Furthermore,

'Timeframe for delivery of this qualification of great concern. Some RTOs deliver this qualification online, face-to-face in as little as 3 days. How can anyone deliver this qualification in 3 days and deem people competent?' (Council 2011)

\#5 Rote learning

Clearly a TAE completed in about 5 to 10 days is insufficient to teach the entire course. However even the nominal 290 hours may be inadequate given that only $20 \%$ of the material is directly relevant to pedagogy. The author submit this entirely inadequate for learning the complex skills required to teach. According to Turner-Bisset:

'...teaching is a deeply complex, intellectual and practical activity. It is a creative act, in which the expert teacher selects from the store of experience and repertoire of teaching strategies and representations, the most appropriate ones for her or his purposes. The danger in focusing only on teaching skills and competencies or standards, as they are now termed, is that it ignores the complex reasoning, thinking and synthesis which underpins the best teaching'. (Turner-Bisset 1999)

Skill is the ability to undertake a specific task which at its simplest level is based on memory and psychomotor coordination. Competency is the ability to perform to a given standard. For example someone has the skill to give a lecture and is deemed competent if they can perform to an industry standard. Training is the acquisition of knowledge and skills in a specific context. Without knowledge the ability to give a presentation is only a skill. Underpinning knowledge such as a deep understanding of the principles of teaching is essential. Skills allied with knowledge result in a trained person. There are various methods that can be used to evaluate the depth of knowledge. Bloom defined three educational objectives referred to as domains namely: Cognitive, Affective and Psychomotor (Bloom 1956). The Cognitive and Psychomotor are directly relevant to the VET sector. The Cognitive domain defines six levels from lower order to higher order learning: Knowledge; Comprehension; Application; Analysis; Synthesis and Evaluation. The lower Knowledge Cognitive domain is characterized by being able to remember but not necessarily understand facts i.e. rote learning. Achieving higher order outcomes requires extensive and dynamic interactions over extended periods of time in various contexts.

Courses with inadequate contact hours and predominantly self-study can only achieve the lowest Cognitive domain of Knowledge which is in effect rote learning. Clearly the quality of an education system cannot exceed the quality of its teachers.

\#6 Rote learners teach rote learning

There is an intrinsic self-perpetuating quality control problem. The minimum qualification to teach the TAE is the TAE itself. The AQTF Users' Guide to the Essential Conditions and Standards for Continuing Registration of Registered Training Organizations (RTOs) require trainers and assessors to hold the Certificate IV in Training and Assessment (TAA40104) or demonstrate equivalence of competencies (Council 2011). This requirement has subsequently been amended to Certificate IV in Training and Assessment (TAE40110). It is possible for a student to have completed the TAE without achieving the higher order cognitive domain levels and then teach the TAE - rote learners teach rote learning. The impact of quality teaching on students cannot be understated.

'Ten years ago, seminal research based on data from Tennessee showed that if two average eight-year-old students were given different teachers - one of them a high performer, the other a low performer - their performance diverge by more than 50 percentile points within three years.' (McKinsey\&Company 2007)

\#7 Mentoring standard

As a quality control mechanism there is a requirement for novice lecturers to be mentored by staff who have completed the TAE. Three Quality Indicators form part of the AQTF Essential Conditions and Standards for Continuing Registration of RTOs (AQTF 2010). These indicators focus on continuous improvement and present data to RTOs that will assist them in the identification of areas for improvement in training and assessment services and meeting the clients' needs.

The learner engagement and competency development indicator focuses on the learner engagement in 
activities expected to facilitate high-quality skills and knowledge outcomes and the learner's perceptions of the quality of their competency development and support received from the RTOs during these processes.

However quality outcomes are entirely dependent on their implementation. As rote learners can only teach rote learning the risk of poor quality performance of the training and assessment services represent a high risk.

\subsection{Alternative Approaches}

The Australian University sector did not have standards for teaching or any requirement for lecturers to complete a teaching qualification. In 2008 the Bradley report recommended significant changes for Australian Universities that included a demand-driven, student-entitlement system with a greater emphasis on accreditation, quality assurance and a quality assurance framework based on externally validated standards (Bradley 2008). Accordingly the Tertiary Education Quality and Standards Agency (TEQSA) was established in 2012 (Department of Industry 2011). TEQSA define a higher education standards framework:

- Provider registration standards

- Qualification standards

- Information standards

- Teaching and Learning

- Research standards

As a quality assurance mechanism to address teaching and learning quality a higher education provider is required to ensure that teaching staff:

- Are appropriately qualified in the relevant discipline for their level of teaching

- Have a sound understanding of current scholarship and/or professional practice in the discipline they teach

- Have an understanding of the pedagogical and/or adult learning principles relevant to the student cohort being taught

- Engage students in intellectual inquiry appropriate to the level of the course of study and unit being taught

- Are advised of student and other feedback on the quality of their teaching and have opportunities to improve their teaching

Significantly the need to have an understanding of pedagogy is not elaborated on regarding how this can be achieved and to what level of expertise.

In order to evaluate how pedagogy could be taught the Postgraduate Certificate in Tertiary Teaching and Learning (PGTT), offered at the University of Southern Queensland (USQ) was analyzed. This course is designed for potential educators who have either a degree or diploma and wish to obtain a qualification in tertiary teaching and learning (Queensland). This award applies educational theories to educators working in both the further and higher education sectors. To complete this course a student must complete two core and two elective units as follows:

Two core units:

- Exploring learning and teaching in Higher Education Contexts

- Assessment Principles and Practices

Two elective units from:

- Principles of Quality Curricula

- Online Pedagogy in Practice

- Teaching \& Learning in Contemporary Contexts

- Scholarship in Higher Education

- Professional Study

This course is marketed as being suitable for academics in both the Further (VET) and Higher Education sectors. A preliminary analysis of the course outlines suggests the primary emphasis is on pedagogy and teaching practices. 
The need to emphasize pedagogy for lecturers in the VET sector is underpinned by recommendations made by the LH Martin Institute and recommendations that included:

'The next review of the Cert IV TAE includes a greater emphasis on broader knowledge of pedagogy, classroom management, understanding learners, student diversity and student engagement.' (Wheelan 2010).

\section{Discussion}

Quality teaching and learning outcomes in the School and VET sectors are highly dependent on the ability of a lecturer to teach. Teaching is defined as the broad range of activities that result in students achieving higher order learning within the Cognitive domain. The compulsory TAE provides instruction in pedagogy but also includes extensive instruction in training packages, AQTF etc. This paper suggests that the pedagogical aspect of the TAE is a minority component. This problem is compounded by significant deviations from nominal contact hours for the TAE resulting in students probably only being able to attain lower order Cognitive domain learning associated with rote learning. Furthermore it is possible for TAE graduates, with only rote learning ability, to become TAE instructors.

\section{Acknowledgements}

This paper would not have been possible without a significant contribution from Philip Jackson.

\section{References}

AQTF. (2010). Essential Conditions and Standards for Continuing Registration.

Bloom, B. S., Egelhart, M. D., Furst, E. J., Hill, W. H., \& Krathwohl, D. R. (1956). Taxonomy of Educational Objectives. Ann Arbour, Michigan, David McKay Company Inc.

Bradley, D. (2008). Review of Australian Higher Education. Canberra City.

Clayton, B., Meyers, D., Bateman, A., \& Bluer, R. (2010). Practitioner expectations and experiences with the Certificate IV in Training and Assessment (TAA40104). Adelaide, Australia.

Company, M. (2007). How the world's best-performing school systems come out on top.

Council, N. Q. (2011). TAA40104 Certificate IV in Training and Assessment Stage 2 Report. Melbourne, Australia, TVET Australia.

Council, N. S. S. (2011). National Skills Standards Council Meeting Communique.

Department of Education, E. a. W. R. (2012). Skills for all Australians. Retrieved from http://www.deewr.gov.au/Skills/Documents/SkillsforAustraliasFuture.pdf

Department of Industry, I., Science, Research and Tertiary Education (2011). Higher Education Standards Framework. Federal Register of Legislative Instruments F2012L00003.

McKinsey \& Company. (2007). How the world's best-performing school systems com out on top.

Moodie, G., \& Curtin, E. (2010). The quality of teaching in VET - evidence. Melbourne, Australia. Queensland, U. o. S. "Postgraduate Certificate in Tertiary Teaching and Learning ".

State of NSW, D. O. E. A. T. P. S. A. C. D. Summary of Quality Teaching Elements. Retrieved June, 2013, from http://www.newcastle.edu.au/Resources/Schools/Education/Pedagogy/2006/SummaryofQuality-JanPoona.p df

Turner-Bisset, R. (1999). The knowledge bases of the expert teacher. British Educatinal Research Journal, 25(1), 39-55.

VetInfoNet. $\quad$ "TAE40110." $\quad$ Retrieved $\quad$ September, $\quad 2012, \quad$ from http://www.vetinfonet.det.wa.edu.au/Course/searchTrainingProduct.aspx

Wheelan, L., \& Curtin, E. (2010). The quality of teaching in VET: overview. Melbourne, LH Martin Insitute for Higher Education Leadership and Management.

\section{Copyrights}

Copyright for this article is retained by the author(s), with first publication rights granted to the journal.

This is an open-access article distributed under the terms and conditions of the Creative Commons Attribution license (http://creativecommons.org/licenses/by/3.0/). 